\title{
O canto alentejano: formas de resistência e horizontes de expetativa $^{1}$
}

\section{Alentejo song: forms of resistance and horizons of expectation}

Enviado em: 30/09/2020

Aceito em: 05/01/2021

Dulce Simões $^{2}$

\section{Resumo}

A inscrição do Cante Alentejano na Lista Representativa do Património Cultural e Imaterial da Humanidade (LRPCIH) da UNESCO em novembro de 2014 criou expetativas nos detentores da herança cultural, que emanam da vontade coletiva pela dignificação de uma expressão cultural de homens e mulheres que têm formas próprias de acção e conquistas que Ihes são imanentes. O passado impõe-se como elemento unificador de uma "comunidade de partilha", definida pela distribuição de espaços, tempos e tipos de atividade que determinaram a maneira de uma classe subalternizada comunicar e fazer política. Neste texto procuro analisar a tensão progressiva entre experiência e expetativa, a partir da multiplicidade de relações sociais e políticas inerentes à hierarquização e domínio dos saberes musicais e às características da sua organização no tempo e no espaço. Os tipos de mudanças incrementais e a apreensão de dados a respeito do canto alentejano, como forma de resistência, convidam a pensar quem define e manipula na contingência, e com que finalidade, os sistemas simbólicos em determinados tempos históricos.

Palavras-chave: Cante Alentejano; Cultura popular; Dominação e resistência.

\begin{abstract}
The inclusion of CanteAlentejano in UNESCO's List of Cultural and Intangible Heritage of Humanity (LRPCIH) created expectations in holders of cultural heritage, whichemanate from the collective will for the dignification of a cultural expression of men and women who have their own forms of action and achievements that are immanent to them. The past imposes itself as a unifying element of a "sharing community", defined by the distribution of spaces, times and types of activities that determined the way for a subalternized class to communicate and make politics. In this text I try to analyze the progressive tension between experience and expectation, based on the multiplicity of social and political relations inherent to the hierarchy and
\end{abstract}

1 - Trabalho realizado no âmbito do projeto pós doutoral "A cultura expressiva na fronteira lusoespanhola" (SFRH/BPD/89108/2012) financiado por fundos nacionais através da FCT- Fundação para a Ciência e a Tecnologia, I. P., no âmbito da Norma Transitória DL 57/2016/cp1453/ct0047.

2 - Doutorada em Antropologia pela Faculdade de Ciências Sociais e Humanas da Universidade Nova de Lisboa, é investigadora contratada no Instituto de Etnomusicologia - Centro de Estudos em Música e Dança (INET-md) da mesma universidade. 
mastery of musical knowledge and to the characteristics of its organization in time and space. The types of incremental changes and the apprehension of data regarding Alentejo singing, as a form of resistance, invite us to think about who defines and manipulates contingency, and for what purpose, the symbolic systems of certain historical times.

Keywords: Cante Alentejano; Popular culture; Domination and resistance.

No es una poesía gota a gota pensada. No es un bello producto. No es un fruto perfecto.

Es algo como el aire que todos respiramos y es el canto que espacia cuanto dentro llevamos.

(CELAYA, 1968, p. 631)

Na Europa, o interesse pela cultura popular surgiu nos finais do século XVIII influenciado pelo ideal romântico de "pureza" e difundiu-se em regiões periféricas, sendo mais tarde apropriado pelos movimentos nacionalistas(BURKE, 1989). O termo "popular" associado à música do campesinato europeu baseou-se num repertório de construção da nação, progressivamente substituído pela designação de folclore. ${ }^{3} \mathrm{Em}$ Portugal, os estudos pioneiros foram produzidos fora da academia, por etnógrafos locais que projetaram a sua visão do mundo sob um cunho estético, submetendo-a ao "círculo do museu e do erudito" (SILVA, 1994, p.101). Durante o Estado Novo (19331974) a cultura popular foi estabelecida "pela ofensiva moralizadora da Igreja e do Estado" e conduziu a um vasto processo de "disciplinação pelo folclore, como instrumento funcional de coação ideológica, de "domesticação" do camponês, "ingénuo e autêntico", detentor das marcas singulares da identidade nacional" (SILVA, 1994, 111-112). Os "verdadeiros valores nacionais" estavam contidos nas práticas e costumes do povo, "dum povo que se mitificava e idealizava ao arrepio do seu próprio índice de subdesenvolvimento" (TORGAL, 1982, p.1438). O discurso sobre a cultura popular, construído na aliança entre o poder político e o científico, ajustou-se ao contexto de cada época, com o propósito de mostrar as relações estratégicas entre os atores sociais que agem por detrás da constituição de identidades culturais (REVEL, 1989, p.47).

3 - Folclore (saber do povo), termo introduzido em 1846 pelo folclorista britânico Williams Thoms, membro fundador da FolkloreSociety (1878), associação destinada à conservação e publicação de tradições populares (GUINOTY SIERRA, 1922, p. 44). 
$\mathrm{Na}$ contemporaneidade ressurgiu numa versão atualizada e autorizada de "património cultural imaterial" (PCI), conceito instituído pela UNESCO que se deslocou do sentido folclórico e nacionalista para se converter em sinónimo de diversidade cultural da humanidade (KIRSHENBLATT-GUIMBLETT, 1995, p.1-13). Em sociedades historicamente marginalizadas, que aspiram à mesma liberdade e dignidade que mobilizaram os seus antepassados, desenvolveram-se formas de cidadania redefinidas estrategicamente na salvaguarda do $\mathrm{PCl}$, que se apresentam soberanas quando proclamadas por um grupo reconhecido pelo Estado como seu detentor (CHEHAN, 2004, p. 72-74). Raymond Williams recorda-nos que numa determinada formação cultural algumas práticas são selecionadas e enfatizadas, enquanto outras são negligenciadas e excluídas. Na hegemonia cultural estabelecida esta seleção é apresentada e passa geralmente com êxito por "passadosignificante", representando uma versão do passado que pretende conectar e ratificar o presente, oferecendo um sentido de continuidade, sem contradizer o status quo (WILLIAMS, 1977, p. 115,116).Neste processo, as diferenças temporais entre o passado e o presente são aniquiladas graças aos simulacros da "atualização", que segundo Henri-Pierre Jeudy é uma maneira de tornar presente o que aparentemente deixou de o ser, subtraindoa temporalidade atribuída ao passado, que se torna a-histórico, para Ihes conferir um "poder de contemporaneidade" (JEUDY, 2008, p. 75). As raízes históricas e políticas das mobilizações pela salvaguarda do $\mathrm{PCl}$, em diferentes lugares do mundo, podem ser encontradas em comunidades indígenas e camponesas despossuídas de direitos, de bens comuns e dos seus patrimónios, como alternativa à destruturação das relações de produção, à precarização e à pobreza (JIMÉNEZ DE MANDARIAGA, 2019, p. 803-812). Como alegou Paula Godinho, será que a salvaguarda do património cultural assegura um gigantesco potencial de sobrevivência após a destruição de modos de vida por parte de governos neoliberais, "empenhados numa cruzada ideológica pejada de inevitabilidades, conjugada com uma economia política favorável às classes dominantes?" (GODINHO, 2012, p.15).

A valorização do $\mathrm{PCl}$ como oportunidade económica, em termos diferentes do lucro, abre um campo de possibilidades à produção de novas ideias e formas de organização coletiva, que podem quebrar o modelo dominante de mercadorização da cultura. As estratégias variam em função de experiências e de repertórios de lutas passadas, de vontades coletivas e de redes de relações sociais que permitem delinear horizontes de esperança. Como assinalou David Harvey, o ideário neoliberal de criação de valor e virtualização da cultura encontra resistências em formações 
culturais e políticas que desempenham um importante papel na diferenciação do grau de aceitação das determinações do mercado livre, frente a outras formas de socialização (HARVEY, 2007, p. 126).As iniciativas coletivas baseadas nos recursos, humanos e culturais, preservam os laços sociais e contribuem para a construção de futuros possíveis em sociedades rurais europeias envelhecidas e economicamente desarticuladas, como no caso da região do Baixo Alentejo, sul de Portugal. ${ }^{4}$

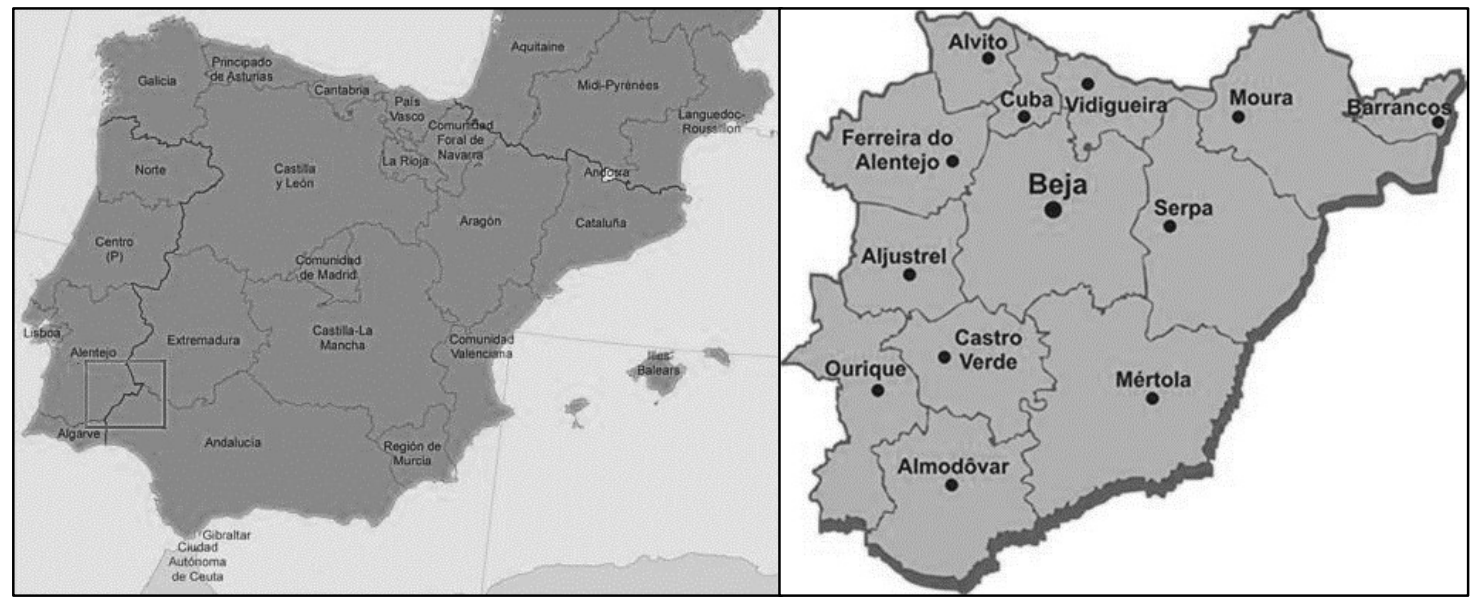

Figura 1: Mapa Portugal/Espanha da União Europeia e mapa do distrito de Beja (Baixo Alentejo).

A candidatura do Cante Alentejano à Lista Representativa do Património Cultural e Imaterial da Humanidade (LRPCIH) da UNESCO mobilizou coletivos a nível institucional (órgãos de soberania, partidos políticos, autarquias locais e igreja), entidades culturais e empresariais, individualidades de diversas áreas (académicas e artísticas) e os detentores da herança cultural, empenhados em reivindicarem "um património de inestimável valor, pertença coletiva de um povo e de uma região, e não mais uma manifestação etnográfica específica do proletariado rural"(GUERREIRO, 2013). A evolução do conceito e o significado do canto posto em valor suscitou "uma aproximação descomplexada e global dos alentejanos à sua expressão vocal mais autêntica"(GUERREIRO, 2013). A inscrição deste género coral polifónico de matriz rural estabeleceu a continuidade de uma prática "objetificada" (HANDLER, 1988, p. 7) como emblema identitário da região do Alentejo. ${ }^{5} \mathrm{O}$ reconhecimento mundial veio criar

4 - Dos oito "elementos" inscritos na LRPCIH da UNESCO três situam-se na região do Alentejo: o Cante Alentejano (2014), fabricação tradicional de chocalhos (2015) e artesanato figurativo de Estremoz (2017). https://ich.unesco.org/es/estado/portugal-PT (consultado a 12/03/2020).

5 - Contribuíram para a seleção, categorização e recontextualização deste modelo performativo os estudos de (Gallop, 1937; Leça, 1940; Delgado, 1955 e Marvão, 1955, entre outros). 
diferentes expetativas, e as dos detentores emanam da vontade coletiva pela dignificação de uma expressão cultural que articula os processos de transformação da sociedade rural com as lutas pelo direito à palavra, de homens e mulheres que têm formas próprias de ação e conquistas que lhes são imanentes. ${ }^{6} \mathrm{O}$ passado impõe-se como elemento unificador de uma "comunidade de partilha", definida pela distribuição de espaços, tempos e tipos de atividade que determinaram a maneira de uma classe subalternizada comunicar e fazer política (RANCIÈRE, 2005 (2000), p.15). Os cantos retratam o imaginário político que desenhou as classes sociais nos campos do sul de Portugal, ancorado num "nós", os trabalhadores, por oposição a "eles", os latifundiários. O que não significa que todos os cantos sejam explicitamente políticos, no sentido de apresentarem modelos programáticos ou estratégicas de ação coletiva, mas expressam sentimentos de pertença e relações sociais baseadas no conflito (POZZI, 2020, p.119-120). As estruturas poéticas estabelecem a relação entre a cultura e o sistema de produção social, por estarem dotadas de estruturas, formas, propósitos e significados em que o político e o social são indissociáveis. A voz poética assume "la función cohesiva y estabilizadora en la cual el grupo social no podría sobrevivir (...) la voz poética agrupa en un único instante - el de la interpretación-, desvanecido tan pronto como ella se calla. (...) La voz poética es memoria en ambos sentidos" (ZUMTHOR apud POZZI, 2020, p. 122-123). A ruralidade inscreve uma marca de intemporalidade que perpetua o passado, como expressão cultural e ação política, e tanto no canto espontâneo e informal como nos repertórios dos grupos corais vislumbra-se uma tensão entre os cantos resgatados de cancioneiros tradicionais e outros intensionalmente concebidos para exortar as experiências da Reforma Agrária, "o tempo mais ditoso, em que o futuro nasceu" ${ }^{7}$ O Alentejo rural do passado, das lutas pelo direito ao trabalho e das conquistas da Revolução de Abril de 1974, opõe-se ao Alentejo contemporâneo, em projeto, aberto a novas formas de ação coletiva. Esta constatação impede-nos de descurar a dimensão social do canto alentejano como prática de resistência, ou de renunciarmos à ruralidade como espaço da experiência, apesar das novas gerações de praticantes não terem experienciado a vida rural nem o trabalho agrícola.

6 - "El cante alentejano, canto polifónico del Alentejo (sur de Portugal)". https://ich.unesco.org/es/RL/elcante-alentejano-canto-polifonico-del-alentejo-sur-de-portugal-01007 (consultado a 12/03/2020).

7 - Moda "Alentejo é Esperança!", autoria de José Borralho, Grupo Coral e Etnográfico "Os Amigos do Alentejo" formado em 1986 no Feijó (Almada). Ouvir em: https://www.youtube.com/watch?v=dql0A8F9hp8 (consultado a 12/03/2020). 
Neste texto procuro analisar a tensão progressiva entre experiência e expetativa, a partir da multiplicidade de relações sociais e políticas inerentes à hierarquização e domínio dos saberes musicais e às características da sua organização no tempo e no espaço. Reinhart Koselleck ensinou-nos que a experiência tem o poder de elaborar acontecimentos passados e torná-los presentes, por estar saturada de realidade e conter no próprio procedimento as possibilidades realizadas ou falhadas. Enquanto a expectativa realiza-se no futuro presente direccionado para o não experimentado, para o que apenas pode ser previsto, funcionando como uma projeção que alia a análise racional do passado com o desejo do porvir (KOSELLECK, 2006 (1979)). Os tipos de mudanças incrementais e a apreensão de dados a respeito do canto como forma de resistência convidam a pensar quem define e manipula na contingência, e com que finalidade, os sistemas simbólicos em determinados tempos históricos.

\title{
Os saberes autorizados e as práticas de resistência
}

\author{
Sou \\ O que comeu o pão \\ Que o diabo amassou. \\ E aqui estou. \\ Cantando o que amo, \\ Cantando o que odeio, \\ Cantando o que sou. \\ (CARVALHO, 1949, p. 15).
}

A primeira referência documental ao canto alentejano remete-nos para o contexto em que o povo se constituiu "objecto da ciência" (CERTEAU, 1989, p.55), ligado à dança "por pares que ficavam horas no baile, andando à roda n'um passo vagaroso, cantando em coro as modas lentas, entoadas em terceiras, prolongadas em sonoridades singulares e doces" (MARCHI, 2010, p. 8). O termo "modas" provém das canções se divulgarem de boca em boca, entre a população rural alentejana, caindo assim em "Moda" (DELGADO, 1955, p.7). O maestro Fernando Lopes-Graça assinalava o caracter voix-de-ville da "canção popular", composta de melodias, novas ou antigas, a que constantemente se adaptavam letras diferentes, ao longo do tempo e de região para região, independentemente de conservar "a essência, o aroma da terra, a marca da sua origem, como selo da sua autenticidade e inspiração popular". Sobre a origem do canto alentejano apresentou duas perspetivas complementares: uma de "sedimentação antiga" difícil de determinar, com origem em diferentes épocas, avançando a hipótese de alguns "espécimes" remontarem a "tempos medievais", e outra de "influência moderna", que não ultrapassaria o século XVIII, de canções de 
estrutura tonal maior-menor ritmicamente simétricas e morfologicamente rudimentares (LOPES-GRAÇA, 1991, p.38-39). O padre António Marvão identificou duas linhas distintas na origem do canto alentejano, que subdividiu em "modas" e "canções alentejanas", remetendo as primeiras para a polifonia clássica arcaica dos séculos XV e XVI, de influência gregoriana, e as segundas para um modelo de folclore musical influenciado pela disseminação da música moderna, do fado à canção popular (MARVÃO, 1955, p. 9-10). Paulo Lima recuou até ao século XVII, a um auto teatral de Trindade (Beja) para situar a origem do repertório e justificar a salvaguarda dos cânticos ao Menino, Janeiras e Reis, três séculos antes do aparecimento dos grupos corais e do canto organizado e institucionalizado, como o conhecemos hoje. ${ }^{8}$

A linguagem da religião poderia ser o último recurso de uma classe subalternizada que não podia exprimir-se e teve de dissimular e "mascarar-se" para fazer ouvir uma ordem cultural diferente. O Alentejo foi considerado pelas autoridades eclesiásticas como "terra de missão", e os costumes religiosos dos seus habitantes refutavam o discurso sobre a propensão dos camponeses para uma visão sagrada do mundo (MATTOSO, DAVEAU, BELO, 1998, p. 35). A observância religiosa mantevese como um hábito urbano a que o campesinato rural alentejano permaneceu alheio, e as próprias autoridades eclesiásticas, receosas desta contaminação, impediram os párocos de residirem fora das vilas e cidades (MATTOSO, DAVEAU, BELO, 1998, p. 36). O anticlericalismo das sociedades rurais do Sul resultava do papel social do padre, representante oficial da Igreja do Estado, ajustar-se aos interesses e conluios do poder dominante dos latifundiários (MARTÍNEZ ALIER, 1968; CUTILEIRO,1971; SIMÕES, 2016). A religião sustentava e equilibrava as sociedades rurais, na ligação entre o latifúndio e a ordem social envolvente, e o trabalhador rural possuía uma dimensão religiosa assimilada em termos da sua própria existência (WOLF, 1976). Michel Giacometti considerava o Baixo Alentejo das regiões mais pródigas do país em cantares alusivos ao nascimento do Menino, e assinalou que o homem alentejano, "por razões a que a sua condição social e económica talvez não seja estranha, canta modas cuja linha severa não impede uma certa ternura ao Menino, nascido em tão

8 - Tratava-se de uma peça de teatro religiosa, que durava cinco horas, da qual foram extraídos textos que entraram posteriormente no repertório do canto alentejano. "Os dias em que o cante vai à igreja", Carla Ferreira, Diário do Alentejo, n. ${ }^{\circ} 1654,3$ de janeiro, 2014, pp. 4-5. 
pobres agasalhos, que até parece impossível, como dirá um dos amigos de Vila Verde de Ficalho (Serpa)". 9

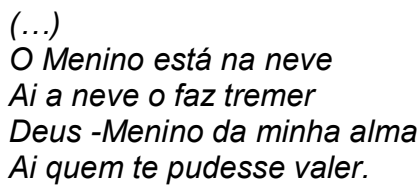

No Natal os trabalhadores rurais dedicavam cantos ao Menino em casa, ou frente à igreja, e nos Reis cantavam à porta das pessoas mais abastadas os "cantos de peditório", ritual comum a povoações rurais do norte e sul de Portugal (MARVÃO, 1955, p. 13). Neste ritual encontramos estratégias de resistência na obtenção de bens imediatos, frutos, doces e algum dinheiro, para mitigar a fome e a escassez de uma classe subjugada pelo sistema latifundiário, que limitava o mercado de trabalho a pouco mais de seis meses (PEREIRA, 1983; BAPTISTA, 1986; GODINHO, 2001, FERNANDES, 2006; SIMÕES, 2016). As "armas dos fracos" foram estratégias de resistência quotidiana, ocultas e dissimuladas, que não visavam a transformação da sociedade ou do Estado, mas evitar o conflito aberto com os patrões e as autoridades em defesa da subsistência das famílias, e os cantos cumpriam essa função (SCOTT, 1985).

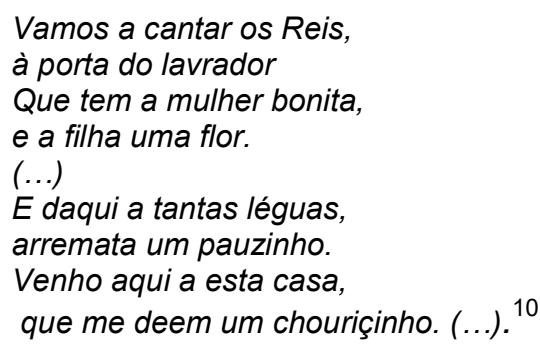

Na linha de E. P. Thompson, a cultura popular consolidava os costumes que serviam os próprios interesses dos subalternos, oferecendo consolo e defesas para o curso de vidas totalmente determinadas e restringidas. Todos os aspectos da vida social, o trabalho, a comunidade, a autoridade e as diversões serviam para ampliar a perspetiva de classe e propiciar a construção de uma cultura distintiva, que encontrou no canto uma poderosa força coletiva, por todas as experiências estarem mediadas

9 - Moda "Deus Menino" excerto da série documental "O Povo que Canta", 11. Programa. Ouvir em: http://www.youtube.com/watch?v=CjbWk9bpmTo(consultado a 12/06/2020).

10 - Moda recordada por José Patrício (Amareleja, 1944), gravada durante a nossa conversa a 3 de janeiro de 2015. Registo audiovisual. Ouvir em: https://www.youtube.com/watch?v=9TlavJC51AM (consultado a 12/06/2020). 
pela mesma visão do mundo (SCOTT, 2003, p. 196). Cantar e dançar formava parte de seus próprios meios de autorregulação; as tabernas eram suas, assim como as festas (THOMPSON, 1979, p.50). Segundo António Gramsci, a cultura popular assumiria, face à cultura dominante, uma posição distinta, de clara contestação (GRAMSCI, 1989) e Mikhail Bakhtin revelou-a claramente na sua obra, em rituais festivos que, disfarçados de forma alegórica, manifestavam uma declaração explicitamente revolucionária dos subalternos, que concebiam a negação da ordem social em que viviam (BAKTHIN, 2002 (1965)). O Carnaval era metáfora da suspensão e inversão temporária da ordem, o tempo em que "o baixo" se tornava alto e "o alto" baixo, o momento da reviravolta, do "mundo às avessas" (BAKTHIN, 2002 (1965), p. 9-10). As forças carnavalescas, lentamente suprimidas pelas elites burguesas e asséticas, surgiam na literatura de forma deslocada e distorcida, como objetos de aversão fóbica e desejo reprimido (HALL, 2003, p. 221-224), quando "o povo, saltando por cima das conveniências prescritas na boa civilidade", usava de uma linguagem demasiadamente licenciosa, "dando livre expansão às tendências coprolálicas, que aliás se revelam quotidianamente" (PIÇARRA, 1899, p. 17). As festas populares representaram uma ameaça ao progresso e aos bons costumes, sendo o período carnavalesco objeto de particular vigilância por ser um tempo favorável "a expressões desmedidas", que propiciavam "condutas dissolutas e inteiramente contrárias à boa economia, tranquilidade e segurança pública e igualmente chocantes com a civilização do século" (CRESPO, 1990, p. 349). O interesse por um povo ao qual se cortou a palavra para melhor o domesticar, sustentava a idealização do popular sob a "auréola que cobria melodias inocentes" (CERTEAU, 1989, p.53), reduzidas a textos e partituras que nos remetem para um mundo rural traduzido para um público erudito e urbano. $^{11}$ A necessidade de codificação em partituras, legíveis apenas por especialistas, "representou um exercício de dominação e exclusão que conduziu à negação da performance e ao anonimato do detentor da tradição, a favor do lugar de origem, do produto musical e do autor do registo" (PESTANA, 2017, p. 135). A moda "Vai colher a silva", que segundo o autor do registo era a "predilecta do povo serpense durante o carnaval", cantava-se em andamento de alegreto, dançada ao meio, nos

11 - Destacam-se as obras pioneiras:Músicas e Canções Populares Coligidas da Tradição (1872) de Adelino António Neves e Melo (1846-1912); Cancioneiro de Músicas Populares (1893, 1895 e 1898), inicialmente publicado em fascículos, de César das Neves (1841-1920) e Gualdino Campos (1847-1919), e Cantos Populares Portugueses (1902-1910) de António Tomás Pires, recolhidos da tradição oral contendo canções provenientes de diversas províncias portuguesas, com predomínio do Alentejo (Leal, 2000. p. 35). 
bailes de roda (NUNES, 1899, p. 41-42). Na atualidade está inscrita no Cancioneiro de Serpa (CORTEZ, 2016 (1994), p. 110-111), e é entoada por cantadores dos grupos corais deste concelho, despojada do sentido chistoso associado às relações amorosas entre rapazes e raparigas.

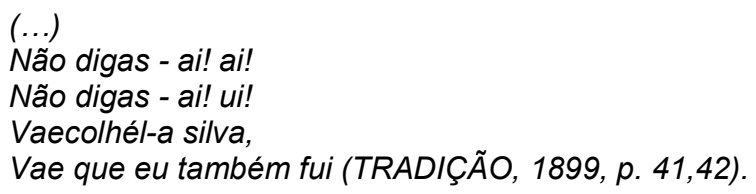

A primeira vaga folclorista contemporânea da I República Portuguesa visava um mundo rural sem contato com a cidade, que a experiência da I Guerra Mundial alterou profundamente. A imagem do mundo exterior e do mundo moral sofreu profundas alterações, até então consideradas impensáveis (BENJAMIN, 2012, p.28). A geração que viveu a I Guerra Mundial foi esmagada por forças destruidoras e os homens regressaram mudos e destroçados dos campos de batalha, despojados de experiências humanas comunicáveis que foram reordenadas em estrofes poéticas, para expressarem diferentes visões do mundo.

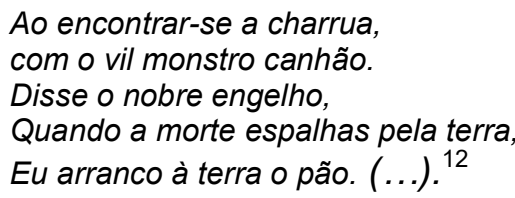

No Cancioneiro Alentejano do padre António Marvão encontramos modas que nos falam de guerras que arrancaram os homens à terra: as campanhas de Mouzinho de Albuquerque em África (1894-1895), a I Guerra Mundial (1914-1918) e a Guerra Colonial (1961-1974). A partir de 1911 os organismos do Estado tentaram incutir sentimentos nacionalistas por meio do serviço militar, a que os rapazes mobilizados respondiam com um "ritual de passagem" preservado em algumas localidades alentejanas. ${ }^{13} \mathrm{Na}$ vila raiana de Barrancos (Baixo Alentejo) o ritual revelava uma representação burlesca com recurso a distúrbios na via pública, como ameaça dos jovens à sociedade, com a qual simbolicamente rompiam e se reconciliavam ao longo do processo ritual (CORNEJOE PIRES, 2003, p. 181-198). O canto reforçava o sentido

12 - "Moda da Charrua", autor anónimo, recolhida na Amareleja (Baixo-Alentejo) (Marvão, 1955, p. 181).

13 - A importância na vida social dos jovens justificou a criação de diversas modas (de autores anónimos) e da canção "Fui às sortes e safei-me", com letra de João Monge e música de João Gil, interpretada por Vitorino no álbum Rio Grande. EMI - Valentim de Carvalho, Música, Lda. 1996. 
do que era comum ao grupo, em estofes poética jocosas, elaboradas em castelhano, que expressavam lealdades abstratas e inquietações concretas.

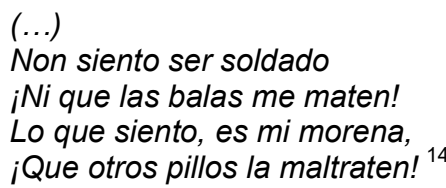

As festas populares e as tabernas foram lugares de liberdade, de trocas ritualizadas e transmissão da cultura popular, em cantos, adivinhas, provérbios e blasfémias (SCOTT, 2003, p. 178). Na cultura europeia, as autoridades e a igreja consideravam as tabernas lugares de subversão, por os subordinados se reunirem depois do trabalho numa atmosfera de liberdade estimulada pelo álcool (THOMPSON, 2004). Os subalternos troçavam do eufemismo das elites e gracejavam sobre os critérios de diferenciação social. ${ }^{15} \mathrm{~A}$ resistência pela ironia não lhes trazia poder, mas ajudava-os a englobar os seus opressores (HERZFELD, 1992, p. 67-77) e a refutar o discurso paternalista das autoridades policiais, de "gente humilde alentejana pouco dada a aventuras, e agarrada como nenhum outro povo à sua terra, e cuja única felicidade é terem trabalho garantido, pão para os filhos, e poderem beber aos domingos uns copos de vinho na taberna". ${ }^{16}$ Os trabalhadores reuniam-se ao domingo para festejarem o dia de folga, após uma semana de trabalho no campo, e entre o vinho e o canto os amigos diziam: "- Só te fica o canto!"

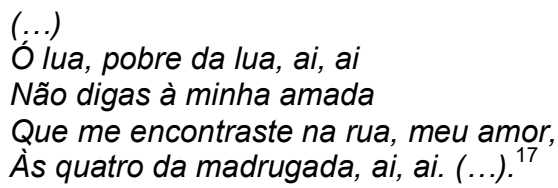

As autoridades civis e militares reprimiam com avultadas multas os homens que cantavam nas ruas $^{18} \mathrm{e}$ os proprietários das tabernas que não cumprissem 0

14 - "Os Quintos de Barrancos". http://estadodebarrancos.blogspot.com/2009/11/baile-dos-quintos-2009em-barrancos.html(consultado a 12/02/2020).

15 - Juan MartínezAlier refere como a alimentação (critério de diferenciação entre señoritos e trabalhadores rurais) era ironizada pelos trabalhadores de Córdoba: "nosotros nos comemos los ricos cardillos, y la deliciosa verdolaga, y ellos se comen el apestosojamón y el asqueroso chorizo"(Martinez Alier,1968 p. 99).

16 - Relatório de Abril de 1936 do comandante do $3^{\circ}$ Batalhão da Guarda Nacional Republicana (GNR) de Beja, capitão Clemente José Juncal, ao Ministro do Interior, sobre as atividades subversivas neste distrito. ANTT. Ministério do Interior, Correspondência do Gabinete do Ministro, mç. 483, cx. 36

17 Moda "Morre o rico, morre o pobre" da autoria de Manuel Torrado Marcelo. CD "Os Arraianos de Barrancos", Faixa 13. 
encerramento obrigatório. ${ }^{19}$ Estas formas de repressão estão documentadas nos arquivos municipais e na memória colectiva, como testemunha o militante comunista Francisco Miguel na sua obra Uma vida na Revolução.

(...) veio o fascismo e os cantos foram proibidos para além das 21 horas. Para se cantar depois das 21 horas era preciso uma licença especial do Administrador do Concelho, mas tirar a licença nem sempre era cómodo e o mais frequente era cantar-se até que a GNR aparecesse. Aparecendo a GNR, ou se fugia, ou se era preso e multado. (...) Com esta repressão fascista aos cantos, o hábito de cantar foi sendo posto de lado. (...) em Serpa toda a vida da terra estava nas mãos dos latifundiários, grandes agrários que paramanterem os seus privilégios anacrónicos, procuravam manter a vida no atraso do ponto de vista cultural, económico e geral (MIGUEL, 1977, p. 2728)

A partir de 1933 o Estado Novo controlou todas as formas de participação social para as dominar ideologicamente, proibindo as manifestações culturais dissonantes com a intenção de criar corpos dóceis, usando a terminologia de Foucault quando se refere a instituições repressivas e totalitárias (FOUCAULT, 1987).Nas sociedades rurais do sul a repressão está associada a décadas de violência, no debelar de lutas reivindicativas de assalariados rurais emineiros, com vítimasmortais inscritas na toponímia das vilas ou caídas no esquecimento. ${ }^{20}$ A Guarda Nacional Republicana (GNR) assumiua função de legítima executora da ordem pública ao serviço dos latifundiários, reprimindo qualquer tipo de manifestação pública. A dominação política, social e económica das elites rurais, a violência das autoridades policiais, e as lutas pela subsistência fazem parte da memória coletiva das classes subalternizadas e inscrevem-se na própria narrativa poética do canto alentejano, como forma de resistência de uma classe com consciência de si.

\author{
(...) \\ Nós somos os trabalhadores \\ Que nos campos trabalhamos \\ Trabalhamos ao rigor \\ Ajudando o lavrador \\ Para ver se nos salvamos.
}

18 A multa aplicada era de cinquenta escudos, acrescida de $20 \%$ para o município, até 1939 . A partir de 1940 foi introduzida a percentagem de $25 \%$ para o Estado e $10 \%$ para Fundo Distrital, num total de sessenta e oito escudos para o autuado. AHMB. Autos de Notícias e Transgressões. F/B, Pastas 1, (1935-1937), Pasta 2 (1938-1943), Pasta 3 (1944-1955).

19 - AHMB. Edital do Governo Civil de Beja de 14 de fevereiro de 1932, artigos $2^{\circ}$ e $4^{\circ}$.

20 - O assassinato de Catarina Eufémia em Baleizão tornou-se num símbolo da luta dos assalariados rurais, "a cristalização de tudo o que tinham sofrido com o latifúndio e um símbolo da Reforma Agrária"(FERNANDES, 2006, p. 23). Outros assassinatos foram inscritos na literatura, por Aquilino Ribeiro em Quando os Lobos Uivam (1958) e José Saramago em Levantado do Chão (1980). 
À semelhança de outros regimes fascistas ou fascizantes europeus, o Estado Novo (1933-1974) alimentou e procurou executar, a partir de órgãos estatais criados para o efeito, "um projeto totalizante de reeducação dos 'espíritos', de criação de um novo tipo de portuguesas e portugueses regenerados pelo ideário genuinamente nacional de que o regime se considerava portador" (ROSAS, 2001, p. 1032). No âmbito da Política do Espírito preconizada por António Ferro, as iniciativas promovidas pelo SPN - Secretariado Nacional de Propaganda (1933-1944) e pela FNAT Fundação Nacional paraa Alegria no Trabalho (1935-1974), em torno da cultura popular, adquiriram centralidade. Diversos atores sociais, instituições e organismos corporativos participaram na produção do discurso oficial unificador, "ao nível das representações conceptuais e político-ideológicas da questão do 'popular', indispensáveis à difusão do ideário do regime". ${ }^{22}$ No universo dos cantos e danças populares as relações dos delegados da FNAT com os associados das Casas do Povo (CP), iniciadas na década de 1930, alcançaram notoriedade nas décadas de 1940 e 1950 na vertente propagandística. ${ }^{23}$ No processo de domesticação dos corpos e das vozes, aliado à depuração e ordenação dos "espécimes" musicais, desapareceram um conjunto de traços associados ao canto coletivo: os grupos mistos, o acompanhamento com instrumentos musicais (viola campaniça, harmónio e pandeiro) e o baile (LIMA, 2013, p.8). A fixação do esquema cantiga-moda, cantiga-moda, impediu que estas tivessem um tempo ilimitado e pudessem cantar a solo quantos

21 - Moda "Nós somos trabalhadores", recolhida por Michel Giacometti em Ferreira do Alentejo, em 1965 (GIACOMETTI, 1981, p. 128-129).

\begin{abstract}
22 - Destacamos neste processo a ação das Casas do Povo, criadas em 1933, do SPN - Secretariado da Propaganda Nacional criado em 1933, seguido do SNI - Secretariado Nacional da Informação, Cultura Popular e Turismo a partir de 1945, da JCCP - Junta Central das Casas do Povo (1945-1974), da FNAT Fundação Nacional para a Alegria no Trabalho (1935-1974), do Gabinete de Etnografia da FNAT criado em 1946, assim como os programas da Emissora Nacional organizados pelo SPN/SNI e FNAT "Alegria no Trabalho" (1941-1972) e "Serão para Trabalhadores" (1941-1974), e as publicações Mensário das Casas do Povo (1946-1971).

23 - As CPs foram organismos fundamentais à manutenção do sistema latifundiário, numa região que durante a I República (1910-1928) fora palco de intensos movimentos sociais. Na sequência das greves de 1910-1912 e da repressão exercida sobre o movimento grevista, os proletários rurais alentejanos entraram no séc. XX como sujeitos históricos, munidos de uma genealogia acoplada a um saber de lutas passadas, como meio de resistência e de ofensiva no terreno da luta de classes que adaptaram a novos contextos políticos e ideológicos (PEREIRA, 1980, 1983).
\end{abstract}


cantadores o desejassem fazer, introduzindo livremente novas estrofes (CABEÇA, 2010, p. 33). Os folcloristas autorizados moldaram os grupos corais à forma que hoje conhecemos, suprimindo o canto espontâneo "passível de promover contestação" e obliterando a sua dimensão política, raramente ausente do terreiro das lutas camponesas que "simbolizou por muito tempo - pelo menos no espírito da gente rural do Sul do Tejo - a solidariedade dos pobres na luta pelos seus direitos elementares" (GIACOMETTI apud OLIVEIRA, 2017 p. 174).

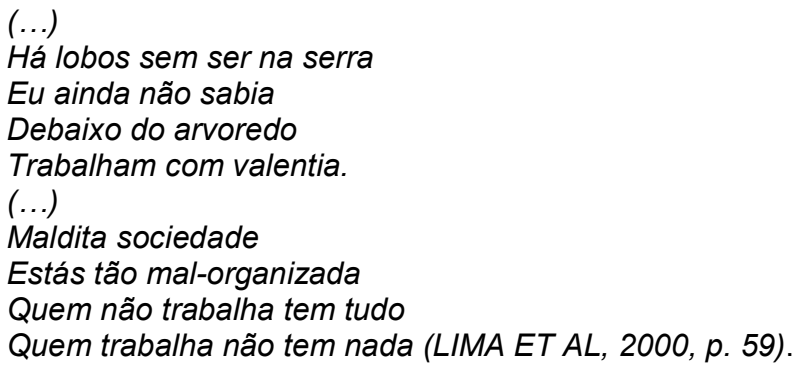

As estrofes poéticas da moda "Há lobos sem ser na serra" expressam as desigualdades sociais e a exploração dos grandes agrários, metaforicamente associados aos lobos. Nas palavras de Francisco Honrado, de Vila de Frades, "havia lobos entre nós, eram eles (os latifundiários, os "ricos) que andavam a comer daquilo que a gente produzia sem nunca molhar (suar) cabelo" (LIMA ET AL, 2000, p.20).A moda esteve proibida devido ao conteúdo de intervenção política e social de uma classe subalternizada que estabelecia pelo canto a relação entre política e estética, característica que manterá após a Revolução de Abril de 1974.

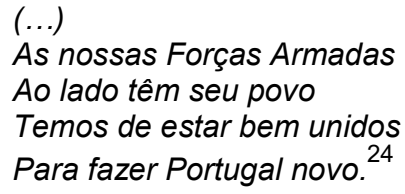

Na alvorada de 25 de Abril de 1974 a Revolução chegou ao Alentejo pela rádio, e as expetativas foram depositadas no Movimento das Forças Armadas (MFA) "como uma espécie de braço armado do Povo" (LOFF, 2015, p. 26). O golpe militar e a revolução política e social consequente reuniam todas as condições para uma rutura com o passado ditatorial, "não apenas na sua dimensão política, mas também nas suas dimensões sociais, económicas e culturais" (LOFF, 2015, p. 26). O (CANCIONEIRO CANTE ALENTEJANO, 2013, p. 42). 
desmantelamento da polícia política e de organizações repressivas foram ações prioritárias, ${ }^{25}$ e nos meses seguintes os organismos corporativos foram extintos ou transformados, mas alguns processos foram lentos e complexos. ${ }^{26}$ No contexto revolucionário o SPN/SNI foi desmantelado, ficando a área de informação e comunicação sob a tutela do Ministério da Comunicação Social criado em maio de 1974, pela relevância da liberdade de expressão na construção da sociedade democrática (DIÁRIO DO GOVERNO, 1974). Na conjuntura revolucionária implementaram-se projetos de animação sociocultural em associações culturais, cooperativas, comissões de trabalhadores e moradores e organizações políticopartidárias, a par das Campanhas de Dinamização Cultural e Acção Cívica do MFA que estabeleceu relações entre o mundo rural e o urbano no maior movimento cultural realizado em Portugal. ${ }^{27} \mathrm{~A}$ FNAT manteve a designação até 1975, passando a denominar-se INATEL - Instituto Nacional para o Aproveitamento dos Tempos Livres dos Trabalhadores. ${ }^{28}$ Michel Giacometti integrou a comissão de restruturação propondo-se a criar o Centro de Documentação Operário-Camponesa, substituto do Gabinete de Etnografia e Folclore, com o objectivo de "documentar a vida e a luta do nosso povo" (OLIVEIRA, 2004, p. 290-291). O Concurso de Cantares Alentejanos e Trajes Regionais, organizado anualmente pela Comissão Municipal de Turismo de

25 - No dia 25 de Abril agentes da PIDE/DGS disparam a partir da Sede por duas vezes, causando dezenas de feridos e quatro mortos: Francisco Carvalho Gesteiro, empregado de comércio de 18 anos, José James HartleyBarneto, de 37 anos, José Guilherme Carvalho Arruda, estudante de 20 anos, e Fernando Luís Barreiros dos Reis, um soldado de 24 anos (OLIVEIRAESANTOS, 2009).

26 - As Casas do Povo foram restruturadas pela Lei $n^{\circ}$. 4/82 de 11 de janeiro, destinada a integrá-las no novo sistema social e político, aproveitando as potencialidades da rede existente. O novo estatuto jurídico de pessoas coletivas de utilidade pública, de base associativa, teve por objectivo o desenvolvimento de atividades de carácter social e cultural em cooperação com o Estado e as autarquias locais, na resolução de problemas que afetassem as populações rurais.

27 - As Campanhas de Dinamização Cultural e Ação Cívica do MFA realizadas entre outubro de 1974 e março de 1975 principalmente no Norte e centro do país, reuniram contribuições provenientes de diversas áreas culturais, teatro, cinema, música, dança e artes plásticas, a par de sessões de esclarecimento sobre a nova conjuntura política. A ideia subjacente de descentralizar as atividades culturais implicou a confrontação com públicos que raramente tinham acesso às artes, plásticas e performativas (ALMEIDA, 2009).

28 - Em 1975 Michel Giacometti fez parte da Comissão de Reorganização da FNAT/INATEL como Director do Gabinete de Etnografia (transformado em Centro de Documentação Operário-Camponesa). Como membro da Comissão Cultural do Organismo de Estado - Fundo de Apoio aos Organismos Juvenis (FAOJ) fundou e dirigiu o Plano de Trabalho e Cultura - Serviço Cívico Estudantil, cujo acervo resultante das campanhas desenvolvidas pelo país foram cedidos pelo INATEL à Câmara Municipal de Setúbal em 1979. Os estatutos do INATEL de 29 de dezembro de 1979 deram prioridade à ocupação dos tempos livres dos trabalhadores, embora mantivesse ao mesmo tempo "a tradição cultural popular portuguesa, que procura preservar em toda a sua autenticidade". https://www.inatel.pt/Fundacao/INATEL(2)/Fundacao/Historia/Do-INATEL-a-Fundacao-INATEL/Do-INATEL-a-Fundacao-INATEL/A-passagem-aInstituto-INATEL.aspx (consultado a 20/03/2020). 
Beja, com o apoio SPN/SNI e da FNAT, foi substituído por um festival de modas livres regionais, designado de "Grande Festa dos Trabalhadores" (DIÁRIO DO ALENTEJO, 1974). Na festa participaram dezasseis grupos corais, e o grupo da Casa do Povo de Barrancos apresentou a moda "Os campos abandonados", exprimindo "os sentimentos de alegria do povo rural pela nova conjuntura política" (LUZEIRO, 1974).

$$
\begin{aligned}
& \text { (...) } \\
& \text { O que vem acontecendo } \\
& \text { Neste nosso Portugal } \\
& \text { Ganhando mal para comer } \\
& \text { Assim não pode viver } \\
& \text { O trabalhador rural. } \\
& \text { Os campos abandonados } \\
& \text { não os mandam cultivar } \\
& \text { É tão linda a agricultura } \\
& \text { Sendo ela mãe da fatura. } \\
& \text { Não se pode abandonar. }
\end{aligned}
$$

No Alentejo diversas classes sociais movimentaram-se contra "os campos abandonados", em função dos seus interesses. Os latifundiários e os grandes empresários agrícolas foram os primeiros a organizarem-se em defesa do capitalismo agrário. Em maio de 1974 criaram a Associação Livre de Agricultores (ALA) e apresentaram o "Programa para uma reestruturação agrícola", mostrando ao país que tipo de política de "dinamização da agricultura" e de "reforma gradual da estrutura fundiária" estavam dispostos a aceitar sem alterarem o status quo (PIÇARRA, 2013, p.60). Em junho de 1974 os assalariados rurais organizam-se em torno de sindicatos distritais, a partir de reuniões convocadas por núcleos de trabalhadores com ligações a lutas passadas e ao Partido Comunista Português (PCP) (PIÇARRA, 2013, p. 61). A luta pelo direito ao trabalho e a melhores salários que marcaram as movimentações sociais nos campos do sul nas décadas de 1940-1950, continuadas pela greve das oito horas de trabalho de 1962 que cobriu toda a região do Alentejo, consolidaram a adesão dos assalariados rurais ao Partido Comunista Português (PCP) em localidades onde a história política e a resistência à ditadura moldaram a identidade dos seus habitantes (FERNANDES, 2006). No Alentejo o comunismo era um fato cultural, como "expressão de um profundo sentimento igualitário" que "impregnou a vida de muitos homens e mulheres de uma forma coletiva" (PEREIRA, 1983, p. 224). A constituição

29 - Manuel Torrado Marcelo "Chicuelo" (Barrancos, 1936) filho de trabalhadores rurais, foi ferreiro, contrabandista, trabalhador rural em campanhas em França, músico da Banda Filarmónica Barranquense, cantador e autor de modas que fizeram parte dos repertórios dos grupos corais de Barrancos. 
de um saber histórico de lutas e a utilização desse saber no contexto revolucionário conduziu à criação de estruturas sindicais locais, por freguesia, que encontraram nas CP o apoio logístico necessário à ação política. Os sindicatos rurais avançaram numa primeira fase com cadernos reivindicativos que exigiam aumentos salariais e garantias de emprego, negociados a nível concelhio com os proprietários rurais da $\operatorname{ALA} .{ }^{30} \mathrm{~A}$ política agrícola do Estado estava em consonância com o Programa do MFA, na concretização de medidas que dinamizassem a agricultura e possibilitassem o aumento da produção com a "reforma gradual da estrutura fundiária". A partir de janeiro de 1975 o Partido Socialista (PS) criticou a política da Secretaria de Estado da Agricultura, o PCP reformulou a política agrária na I Conferência dos Trabalhadores Agrícolas do Sul, centrando-a na luta pelo pleno emprego (VARELA E PIÇARRA, 2016, p. 1193-1194)e o MFA passou a defender "uma reforma agrária que elimine o latifúndio e limite as grandes explorações agrícolas capitalistas" (PIÇARRA, 2013, p. 67). O movimento dos assalariados rurais pelo direito ao emprego conduziu a níveis elevados de eficácia política, entendendo-se esta "como a confiança dos indivíduos na sua capacidade de influenciarem as decisões governamentais" (BAUM, 1998, p.714). A conflitualidade entre assalariados rurais e empresários agrícolas agudizou-se, e o Estado foi obrigado a intervir em grandes explorações agrícolas, através de um decreto que conferia ao governo o direito de expropriar "empresas privadas, individuais ou colectivas", que não contribuíssem "para o desenvolvimento económico do País e para a satisfação dos interesses superiores da colectividade nacional". ${ }^{1}$

As expetativas depositadas na imagética POVO-MFA refletiram-se na politização dos grupos corais alentejanos e em repertórios que correspondiam ao sentimento de esperança na Revolução e na Reforma Agrária. As modas surgiam com novas letras sob melodias antigas, ou sob canções de intervenção como "Grândola Vila Morena" de José Afonso, que foi o santo-e-senha musical da Revolução como expressão do princípio irrevogável de que "o povo é quem mais ordena". A politização das práticas e dos temas foi em larga medida endógena, com os grupos corais a conquistarem as ruas e a alargarem os espaços de atuação a comícios e manifestações de trabalhadores. No Alentejo e na diáspora formaram-se novos grupos coraise o primeiro

30 - Nos meses de novembro e dezembro de 1974 foram distribuídos, no distrito de Beja, mais de mil assalariados rurais por explorações agrícolas, processo fortemente contestado por grandes agrários que em muitos casos não pagaram os salários aos trabalhadores (VARELA E PIÇARRA,2016,p. 1191).

31 - Decreto-lei 660/74, de 25 de novembro, art. ${ }^{\circ}$ 1. Diário do Governo n. ${ }^{\circ}$ 274/1974, $1^{\circ}$ Suplemento, Série I de 1974, pp. 11-25. 
coral feminino nasceu no contexto da Reforma Agrária. ${ }^{32} \mathrm{~A}$ Reforma Agrária efetivou-se no IV Governo Provisório (1975) de Vasco Gonçalves, tendo por ministro da agricultura Fernando Oliveira Baptista, e o sonho "da terra a quem a trabalha" concretizou-se nos campos do sul. ${ }^{33}$ Os assalariados rurais alentejanos reergueram-se como sujeitos históricos ao efectuarem "a maior ocupação de terras privadas bem sucedida na história do proletariado rural da Europa ocidental" (BAUM, 1998, p.709). Entre Dezembro de 1974 e Novembro de 1975 foram ocupados mais de um milhão e cem mil hectares de terra, em que se estabeleceram quinhentas unidades coletivas de produção (UCP) geridas por trabalhadores(as) que controlaram em comum a terra e os meios de produção (BAPTISTA, 1986, p.411). Ao ocuparem as terras e organizarem-se em UCP e cooperativas, homens e mulheres envolveram-se pela primeira vez na vida política, económica e social das suas vilas e aldeias e concretizaram "uma Revolução na Revolução" (MURTEIRA, 2004), ${ }^{34}$ aumentando o emprego e a produção agrícola. Segundo Fernando Oliveira Baptista entre 1975-1976 o número de postos de trabalho fixos aumentou de 11.100 para 44.100 , e os postos eventuais de 10.600 para 27.800. As culturas de sequeiro que antes da ocupação das terras era 85.000 ha passou para 255.000 ha, e o regadio de 7.000 hectares para 16.000 (BAPTISTA, 2001, p. 183, 184).

No VI Governo Provisório (1975-1976) iniciaram-se as primeiras cedências aos interesses do capitalismo agrário, e aumentou a base social afeta ao Partido Socialista (PS) entre os trabalhadores da Reforma Agrária. O poder dos mercados e as políticas governamentais conduziram a uma ofensiva contra as UCP/Coop, na falta de apoios financeiros e redes de escoamento da produção, a par das diferenciações relativamente aos resultados económicos obtidos (BAPTISTA, 2001, p. 188-189). O golpe militar contra-revolucionário de 25 de Novembro de 1975 alterou a correlação de forças políticas na sociedade portuguesa, com os vencedores a imporem "a

32 - O primeiro grupo coral feminino "Flores de Primavera" de Ervidel (Baixo Alentejo) foi formado em 1979, quando um grupo de trabalhadoras rurais que seguiam cantando nas galenas, para uma manifestação de apoio à Reforma Agrária em Beja, foram desafiadas pelo mestre do Grupo Coral da Casa do Povo de Ervidel a formarem um grupo coral (CABEÇA E SANTOS, 2010).

33 - Ver primeira parte da reportagem da RTP sobre a Lei da Reforma Agrária de 10/09/1975. "Reforma Agrária no Alentejo I". https://arquivos.rtp.pt/conteudos/reforma-agraria-no-alentejo-i/ (consultado a 23/03/2020).

34 - Murteira, António (coord.). 2004. Uma Revolução na Revolução, Reforma Agrária no Sul de Portugal. Porto: Campo de Letras.Em Barrancos as ocupações realizaram-se na $3^{\text {a }}$ fase, que ocorreu entre outubro e dezembro de 1975, dando origem à UCP - Fronteira Alentejana. Piçarra, Constantino. 2004. Obra citada, p. 271. 
consagração da legitimidade eleitoral sobre a legitimidade revolucionária" (ROSAS, 2015, p. 203). O PS vencera as eleições para a Assembleia Constituinte em 1975 e as legislativas em 1976, os órgãos regionais do Ministério da Agricultura prometeram apoio governamental, ao mesmo tempo que exploraram as conflitualidades existentes, de maneira a provocarem cisões nas UCP/Coop (BAPTISTA, 1986, p. 422). Em 1977, o primeiro-ministro Mário Soares (PS) apresentou a proposta de adesão de Portugal à Comunidade Europeia e a reforma agrária tornou-se incompatível com as estruturas sociais e económicas do mercado capitalista e as políticas de convergência europeias. A contra-Reforma Agrária impôs-se pela lei e pela força policial da GNR, frente à resistência dos trabalhadores rurais. A resistência assentava numa tradição enraizada de lutas, na lição de que "um homem só não vale nada", ${ }^{35}$ numa base organizativa apoiada nos Secretariados das UCP/Coop, nos Sindicatos dos Trabalhadores Agrícolas e no PCP (BAPTISTA, 1986, p. 426). Nas vilas e aldeias, por iniciativa das câmaras municipais democraticamente eleitas e das UCP, criaram-se serviços sociais e culturais que contribuíram para melhorar a vida dos trabalhadores rurais e alterar radicalmente a ordem social dominada pelas elites agrárias.

O triunfo do mercado ganhou ímpeto após a adesão de Portugal à União Europeia (1986), e o declínio da questão social da terra evidenciado pela Reforma Agrária, associado à erosão demográfica dos assalariados rurais, favoreceu esse triunfo (BAPTISTA, 2004, p. 42). A Política Agrícola Comum (PAC) condicionou os destinos da terra e reforçou a propriedade fundiária. A questão social da terra deslocou-se para a questão do espaço e a protecção ambiental, com novas procuras urbanas a imporem o lazer e a paisagem. O processo de desruralização avançou através da desconstrução do sustentáculo da agricultura enquanto suporte produtivo económico, da herança cultural exposta à "cultura mundo", e da transformação do espaço rural em "paisagem transgénica" (DOMINGUES, 2012). A leitura do rural foi condensada e reinventada numa mistura de nostalgia, ucronia e espetáculo, em múltiplas representações culturais e turísticas ${ }^{36}$ e nas estrofes poéticas dos cantos alentejanos.

35 - Como afirma Armanda Garrusca na última página da obra Seara de Vento, de Manuel da Fonseca.

36 - Turismo de Portugal - Alentejo. https://www.visitportugal.com/pt-pt/destinos/alentejo (consultado a 30/04/2020). 


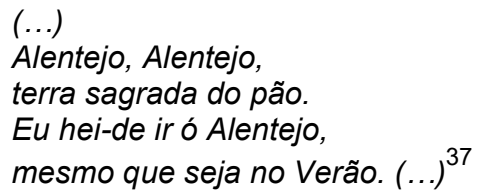

O Alentejo "terra sagrada do pão" modificou-se com a exploração agrícola intensiva da oliveira, que articula a alta tecnologia com a mão-de-obra de trabalhadores emigrantes sem direitos, ao serviço de multinacionais desterritorializadase de patrões sem rosto. O triunfo do capitalismo agrário e da globalização económica é visível em explorações que ameaçam o ecossistema, mas também estimula a imaginação de homens e mulheres que encontram no canto uma forma de expressar o futuro que não querem.

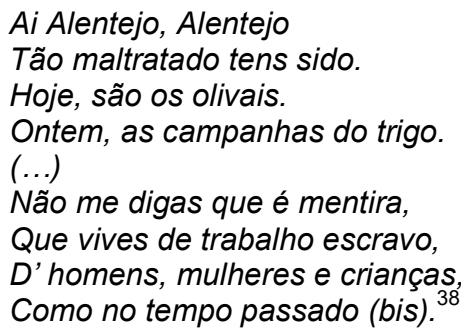

\section{O canto como arma carregada de futuro}

Os Estados e as regiões continuam a necessitar de narrativas que legitimem simbolicamente as comunidades fragmentadas pelo desenvolvimento capitalista, e o $\mathrm{PCl}$ parece servir para expressar desejos e inquietações. A consolidação da "máquina patrimonial", como dispositivo de governança direcionado para a produção e captura de imaginários simbólicos, vislumbra-se como recurso em sociedades marginalizadas pelas economias políticas neoliberais. O patrimonialismo articula diversos interesses, económicos, sociais e políticos, mas também reconstrói o sentido do comum a partir de práticas culturalmente enraizadas. Estas reativam os saberes, estimulam a imaginação e apelam a novas formas de organização coletiva que as sociedades necessitam na actualidade. Neste sentido, devemos questionar os mecanismos

37 - "Alentejo, Alentejo", autor anónimo, moda do repertório do Grupo Coral e Etnográfico da Casa do Povo de Serpa. Ouvir em: https://vimeo.com/253888666 (consultado a 30/06/2020).

38 - "Ai Alentejo, Alentejo" (2019), letra e música de Francisco Barão (Aldeia Nova de São Bento, 1955) cantador do grupo coral "Os Amigos do Alentejo do Feijó" (1986) e fundador do grupo de música tradicional "Rumores de Além-Tejo" (2016) com Joana Barão (Beja, 1991) e Paulo Bicho (Almada, 1966). Ouvir em: https://www.youtube.com/watch?v=2aZ4WyKoqZ0 (consultado a 30/06/2020). 
culturais e ideológicos inerentes aos processos de patrimonialização, mas centrar aatenção nas experiências e expetativas dos detentores da herança cultural, de maneira a compreendermos as bases materiais da adequação ou resistência aos processos de mercadorização da cultura. O desafio consiste em convertermos o $\mathrm{PCl}$ num ativo campo de agenciamento social alternativo e contra-hegemónico, através do reconhecimento das práxis de socialização como armas carregadas de futuro.

\section{Referências Bibliográficas}

ALMEIDA, Sónia. Camponeses, Cultura e Revolução. Campanhas de Dinamização Cultural e Acção Cívica do MFA (1974-1975). Lisboa: IELT-Colibri, 2009.

BAKTHIN, Mikhail. A Cultura Popular na Idade Média e no Renascimento: O contexto de François Rabelais. São Paulo: Hucitec, Annablume Editora, 2002 (1965).

BAPTISTA, Fernando Oliveira. "Trabalhadores Agrícolas e Agricultores familiares. Dez anos de factos, debates e projectos". Revista Critica de Ciências Sociais, n 18/19/20, 1986.

BAPTISTA, Fernando Oliveira. "O 25 de abril, a sociedade rural e a questão da terra".IN Brito, José Maria Brandão (Dir.). O País em Revolução. Lisboa: Editorial Notícias, 2001, pp. 133-207.

BAPTISTA, Fernando Oliveira. "Espanha e Portugal, um século de questão agrária".IN Freire, Dulce; Fonseca, Inês e Paula Godinho (coord.). Mundo Rural. Transformação e resistência na Península Ibérica (Século XX). Lisboa: Edições Colibri, 2004.

BAUM, Michael. "Autogestão e cultura política: o impacto da reforma agrária no Alentejo vinte anos depois". Análise Social, vol. xxxiii (148),1998.

BENJAMIN, Walter. Sobre a Arte, Técnica, Linguagem e Política. Lisboa: Relógio de Água,2012.

BURKE, Peter. Cultura popular na idade moderna. Europa 1500-1800. São Paulo: Companhia das Letras, 1989.

BORTOLLOTO, Chiara. A salvaguarda do património cultural imaterial na implementação da Convenção da UNESCO de 2003. Memória em Rede, 3, n. 4, 2011, pp. 1-13.

CABEÇA, Sónia Moreira e SANTOS, José Rodrigues dos. "As mulheres no Cante Alentejano".INProceedings of the International Conference in Oral Tradition. Ourense: Concello de Ourense, 2010.

CANCIONEIRO CANTE ALENTEJANO. Câmara Municipal de Serpa, 2013.

CARVALHO, Raul. "As sombras e as vozes". Obras de Raul de Carvalho. Lisboa: Caminho, (1949) 1993. 
CELAYA, Gabriel. "La poesía es un arma cargada de futuro". Poesías Completas. Madrid: Aguilar, 1968.

CERTEAU, Michel e DOMINIQUE, Julia. "A beleza do morto: o conceito de "cultura popular"..IN Revel, Jacques et al. A Invenção da Sociedade. Lisboa: Difel, 1989.

CHOAY, Françoise. A alegoria do património. São Paulo: Editora Unesp, 2001.

CORNEJO, Mónica e PIRES, Ema. "Una fiesta y varias fronteras: los Quintos de Barrancos (Portugal) y Noblejas (España)". Revista de Antropología Social, 12, pp. 181-198, 2003.

CORTEZ, Maria Rita Ortigão Pinto. Cancioneiro de Serpa. Câmara Municipal de Serpa, 2016 (1994).

CREHAN, Kate. Gramsci, Cultura e Antropologia, Lisboa: Campo da Comunicação, 2004.

CRESPO, Jorge. A História do Corpo. Lisboa: Difel, 1990.

CUTILEIRO, José. Ricos e Pobres no Alentejo. Lisboa: Livros Horizonte, 2004 (1971).

DELGADO, Manuel Joaquim.Subsídio para o Cancioneiro Popular do Baixo Alentejo, vol. II, Lisboa, 1955.

DIÁRIO DO ALENTEJO, n 12819, de 29 de junho de 1974.

DIÁRIO DO GOVERNO, I Série, n. ${ }^{\circ} 113$, de 15 de maio de 1974.

DOMINGUES, Álvaro. Vida no Campo. Porto: Dafne Editora, 2012.

FERNANDES, Margarida. Terra de Catarina. Do Latifúndio à Reforma Agrária. Ocupação de Terras e Relações Sociais em Baleizão, Oeiras, Celta Editora, 2006.

FOUCAULT, Michel. “Os corpos dóceis”. IN Vigiar e Punir. Petrópolis: Vozes, 1987.

GALLOP, Rodney. Cantares do Povo Português: estudo crítico, recolha e comentário. Lisboa: Instituto de Alta Cultura, 1960 (1937).

GIACOMETTI, Michel. Cancioneiro Popular Português. Lisboa: Círculo de Leitores, 1981.

GODINHO, Paula. Memórias da resistência rural no sul: Couço (1958-1962). Oeiras: Celta Editora, 2001.

GODINHO, Paula. "Uso da memória e práticas do património. Alguns trilhos e muitas perplexidades". IN Godinho, Paula (coord.). Usos da Memória e Práticas do Património. Lisboa: Edições Colibri, 2012.

GRAMSCI, António. Literatura e Vida Nacional. Rio de Janeiro: Civilização Brasileira,1989.

GUERREIRO, José Francisco Colaço. "Cante Alentejano: a evolução do conceito". Correio do Alentejo, 6/06/2013. http://www.correioalentejo.com/?opiniao=1157\&page_id=56 (consultado a 12/03/2020). 
GUINOT Y SIERRA, Alejandro. Historia del Folklore. Orígenes en todos los Paises hasta 1890. Sevilla: Hijos de GuillermoÁlvarez Impressores, 1922.

HALL, Stuart. "Para AllonWhite: metáforas de transformação", IN LivSovik (org.) Da Diáspora: Identidades e mediações culturais / Stuart Hall. Belo Horizonte: Editora UFMG, 2003, pp. 221-224

HANDLER, Richard. Nationalism and the Politics of Culture in Quebec. Madison: The Wisconsin University Press, 1988.

HARVEY, David. Breve historia del Neoliberalismo. Madrid: Ediciones Akal, 2007.

HERZFELD, Michael. “La Pratique des Stéréotypes”. L'Homme, 32, 1992. pp. 67-77.

JEUDY, HENRY-PIERRE. La machinerie patrimoniale. Paris: Circé, 2008.

JIMÉNEZ DE MADARIAGA, Celeste. "El turismo patrimonial: la cultura 'en venta'”, IN Juan Antonio Márquez Domínguez e Jorge Llamas Chávez (dir.) Hélices y anclas para el desarrollo local. Diputación de Huelva, 2019, pp. 803-812.

KIRSHENBLATT-GIMBLETT, Barbara. "Theorizing Heritage". Ethnomusicology, 39, 1995, pp. 367-380.

KOSELLECK, Reinhart. Futuro Passado. Contribuição à semântica dos tempos históricos. Rio de Janeiro: Contraponto, Ed. PUC, 2006 (1979).

LEAL, João. Etnografias Portuguesas (1870-1970). Cultura Popular e Identidade Nacional. Lisboa: Publicações Dom Quixote, 2000.

LEÇA, Armando. Da Música Popular do Baixo Alentejo. Beja, 1940.

LIMA, Paulo (coord.). Ao Romper da Bela Aurora: antologia poética de tipo tradicional e popular de Cuba. Câmara Municipal de Cuba, 2013.

LIMA, Paulo, et al. "No Paraíso Real. Tradição, revolta e utopia no sul de Portugal". IN O Canto do Som, Câmara Municipal de Castro Verde, 2000.

LOFF, Manuel. "Estado, democracia e memória: políticas públicas e batalhas pela memória da ditadura portuguesa (1974-2014)".IN Loff, M. Piedade, F. e L. C. Soutelo (coord.). Ditaduras e Revolução - Democracia e Políticas da Memória, Coimbra, Almedina, 2015, pp. 23-143.

LOPES-GRAÇA, Fernando. A Canção Popular Portuguesa. Lisboa: Caminho,1991.

LUZEIRO, “Cantares Alentejanos”, julho, 1974, p. 1.

MARCHI, Lia; PIEDADE, Celina da; MORAIS, Domingos. Caderno de Danças do Alentejo. Pédechumbo, v.1, 2010.

MARTÍNEZ ALIER, Juan. La Estabilidad del Latifundismo. Paris: Ediciones Ruedo Ibérico, 1968.

MARVÃO, António. O Cancioneiro Alentejano: Corais majestosos, coreográficos e religiosos do Baixo Alentejo, Beringel: Editorial Franciscana, 1955.

MATTOSO, José; DAVEAU, Suzanne e BELO, Duarte. Portugal. O sabor da terra. Baixo Alentejo. Lisboa: Círculo de Leitores, 1998. 
MIGUEL, Francisco. Uma vida na Revolução. A Opinião, 1977, p. 27-28.

MURTEIRA, António (coord.). Uma Revolução na Revolução, Reforma Agrária no Sul de Portugal. Porto: Campo de Letras, 2004.

NUNES, Manuel Dias. "Modas-estribilhos alentejanas”. A Tradição, 3, 1899, pp. 41-42.

OLIVEIRA, Luísa Tiago de. Estudantes e Povo na Revolução. O Serviço Cívico Estudantil, 1974-1977. Oeiras: Celta Editora, 2004.

OLIVEIRA, Luísa Tiago de Oliveira e SANTOS, Isabel Gorjão. "A ocupação da sede da PIDE/DGS em 1974". Ler História, 57, 2009, pp. 125-134.

OLIVEIRA, Luísa Tiago de. "O Alentejo de Michel Giacometti". IN Cantar no Alentejo. A Terra, o Passado e o Presente. Estremoz Editora, 2017.

PEREIRA, José Pacheco. "As lutas sociais dos trabalhadores alentejanos: do banditismo à greve". Análise Social, vol. XVI, 61-62, 1980, pp. 135-156.

PEREIRA, José Pacheco. Conflitos Sociais nos Campos do Sul de Portugal. Mem Martins: Europa-América, 1983.

PIÇARRA, Constantino. "A política agrária e as movimentações sociais nos campos do Sul, do 25 de Abril de 1974 ao 11 de março de 1975". Crítica e Sociedade: revista de cultura política. v.3, n.2, 2013, pp. 57-70.

PIÇARRA, Ladislau. “O Carnaval”. A Tradição, 2, p. 17-20, 1899.

POZZI, Pablo, "Transmitiendo el sentido común: Los cánticos y el comportamiento colectivo". Trabalhos de Antropologia e Etnologia, 60, 2020. pp. 119-120.

RANCIĖRE, Jacques. A partilha do sensível: estética e política. São Paulo: Editora 34, 2005 (2000).

REVEL, Jacques. A Invenção da Sociedade. Lisboa: Difel, 1989.

ROSAS, Fernando. "O salazarismo e o homem novo: ensaio sobre o Estado Novo e a questão do totalitarismo". Análise Social, vol. XXXV, 157: 1032, 2001.

ROSAS, Fernando. "Ser e não ser: A Revolução portuguesa de $74 / 75$ no seu $40^{\text {a }}$ aniversário". IN Loff, Manuel, Piedade, Filipe e Luciana C. Soutelo (coord.), Ditaduras e Revolução - democracia e políticas da memória, Coimbra, Almedina, 2015, pp.195$205 .$.

SCOTT, James C. Weapons of the Weak: Everyday Forms of Peasant Resistance. New Haven and London, Yale University Press, 1985.

SCOTT, James C. Los Dominados y el Arte de la Resistencia. México: Editorial Txalaparta, 2003.

SILVA, Augusto Santos.Tempos cruzados: Um estudo interpretativo da Cultura.Porto: Edições Afrontamento, 1994.

SIMÕES, Dulce.A Guerra de Espanha na raia luso-espanhola. Dominação, resistências e usos da memória. Lisboa: EdiçõesColibri, 2016. 
THOMPSON. E. P. Tradición, Revuelta y Conciencia de Clase. Barcelona: Editorial Crítica, 1979.

THOMPSON, E. P. A Formação da Classe Operária Inglesa. São Paulo: Paz e Terra, 2004.

TORGAL, Luís Reis; AMADEU, Carvalho Homem de. "Ideologia salazarista e «cultura popular» - análise da biblioteca de uma casa do povo". Análise Social, vol. XVIII (7273-74), 1982.

TRADIÇÃO, A. 3, 1899, pp. 41-42.

VARELA, Raquel e PIÇARRA, Constantino. "A reforma agrária nos campos do sul de Portugal (1975): uma revolução na revolução". Estudos Ibero-Americanos, Porto Alegre, v. 42, n. 3, 2016, pp. 1189-1218.

WILLIAMS, Raymond. Marxism and Literature. Oxford/ New York: University Press Inc., 1977.

WOLF, Eric. Sociedades Camponesas. Rio de Janeiro: Zahar Editores, 1976. 